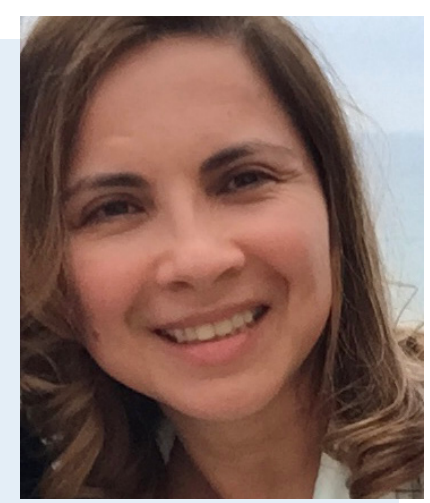

I

I
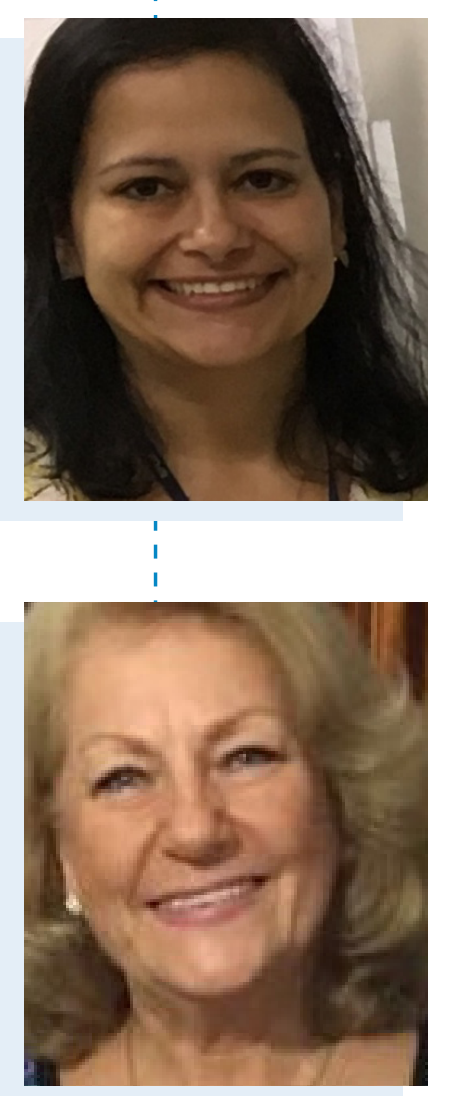

I

I

1

I

I

1

I

I

I

I

i

I

I

I

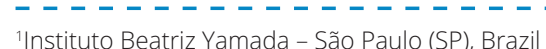

¿Universidade Federal de São Paulo - São Paulo (SP), Brazil

3Hospital Universitário da Universidade de São Paulo - São Paulo (SP), Brazil

Corresponding author: Beatriz Farias Alves Yamada - Instituto Beatriz Yamada - Av. Dr. Vital Brasil, 305 - CEP: $05503-001$ - São Paulo (SP), Brazil.

E-mail: iby@institutobeatrizyamada.com.br

\section{A little history about ESTIMA Journal}

\author{
Um pouco de história da Revista ESTIMA
}

Un poco de historia de la Revista ESTIMA

Beatriz Farias Alves Yamada', Leila Blanes², Noemi Marisa Brunet Rogenski ${ }^{3}$
ORCID IDS

HOW TO CITE

Yamada BFA (D) https://orcid.org/0000-0001-6673-6756 Yamada BFA, Blanes L, Rogenski NMB (2018) Blanes L (D) https://orcid.org/0000-0002-6922-7719 A little history about ESTIMA Journal - Braz J Rogenski NMB (1) https://orcid.org/0000-0002-1085-6158 Enterestomal Ther, 16: e1618. doi: 10.30886/

To realize this editorial, years after the experience of founding this journal, demands of us a certain mnemonic work, since it is already 15 years of history since its origin. An ambiguous task, because it is somewhat herculean and at the same time, simple. Herculean by the mental effort with what to say now, having already spent so much time. But simple, for being a living history, the legitimate "mothers" of Estima. Thus, in thinking about the task, came from the tunnel of time a historical cadence: the idea, the exchange, the planning, the implantation and the celebration. Looking back, we were at the same time projected for the Now and the Future of this journal, which undoubtedly has fulfilled its mission within the Brazilian Stomatherapy and, why not, worldwide.

\section{Idea}

The idea was born of a necessity. In 2002, when we assumed the management of the Brazilian Association of Stomatherapy (SOBEST), this was already work schedule. The identified necessity was simple: there was no national vehicle that could democratize knowledge. This absence was clear, but the filling of this gap was somewhat complex, because of our inexperience in this matter. From the idea was born the exchange.

\section{Exchange}

The exchange came from internal dialogue and with others, aiming to learn the experience by the exploration of the environment. We hear incentives and discouragement. But we retain only the incentives, because from desire or even from ignorance emerges the force. This could even be interpreted as a certain stubbornness in the eyes of skeptics or cowards, but it was not: it was a vision of the future, courage and conviction that the necessity should be overcome and the gap filled. 


\section{Planning and Deployment}

Idea and exchange adjusted and a strong editorial board formed, it was the time of the search for someone more expert that could amplify our good will. And so, the partnerships were born. It was necessary to involve others in the project: journalists, commercial area, graphic etc. We needed to put the editorial project on paper. Choose a name, make a record, create a brand. But it took much more than that: publication material, achieved with requests met. Thankful for the generous!

The journal was named Estima. Although there was no consensus among the founding publishers, it was the decision of the majority. We were convinced, by the idealizer of it (Luis Carlos Rufo), that this word would have total resonance with Stomatherapy.

\section{Celebration}

After the previous steps, the big day arrived to present it to the public. And that deserved a big party. It was a very short time since its conception, undoubtedly achieved with many passionate arms, until its launch, at the 1st Brazilian Symposium on Stomatherapy, Pompeia Convention Center-SP; a night of glamor, in which also happened the first TiSOBEST. Thus, it was coined on June 15, 2003 as the launch and official date of the journal. So, your birthday.

It was many years of intense work, involving many key people: Luis Carlos Rufo (journalist and plastic artist), Luciene Marinho (responsible for commercial management), Moises (NorthGraph Press), Keila Cristiuma and Viviane Bueno (journalists) and Fábio Luiz Alecio (graphic designer). To which we are thankful.

We thank Luis Carlos Rufo for all the covers of the journal. Cheerful, full of life and art to soften what was kept in the often colored contents of clinical cases of injured bodies.

\section{Indexing steps}

After the initial phase, there were so many other years dedicated to the search for indexation. The doors were closed in Brazil for a journal society that did not have the same weight of a university. What has it not happened with international databases. The first indexing by CUIDEN was a moment of glory. Already we had something that much is demanded of the journals, a referendum of which it had content and continuity. Since then, new indexations have been leveled thanks to the meticulous work of Leila Blanes.

Our trajectories as editor-founders were different. But some things we have in common: triple motherhood in the early years of this journal, involvement, passion, humility, resilience, perseverance, and the full conviction that we have done something valuable to our society and to the community.

\section{Present and Past}

In these 15 years of Estima's journey, we see a teenager full of life and no existential crisis of a teenager, which is very typical of a well-made mothering. It is already a robust journal and with credibility, being developed along this journey with other helpers. It stopped being printed to follow the trends, gained an increase in its name, as well as new indexing and impact analysis. Anyway, it's ready for adulthood.

Our desire, as founding editor of Estima, is that it has a long life and reaches more and more space in the scientific world. 